\title{
Individual-level loss aversion in riskless and risky choices
}

\author{
Simon Gächter ${ }^{1,2,3}$ (D) Eric J. Johnson ${ }^{4} \cdot$ Andreas Herrmann $^{5}$
}

Accepted: 23 July 2021 / Published online: 23 August 2021

(C) The Author(s) 2021

\begin{abstract}
Loss aversion can occur in riskless and risky choices. We present novel evidence on both in a non-student sample (660 randomly selected customers of a car manufacturer). We measure loss aversion in riskless choice in endowment effect experiments within and between subjects and find similar levels of average loss aversion in both. The subjects of the within study also participate in a simple lottery choice task which arguably measures loss aversion in risky choices. We find substantial heterogeneity in both measures of loss aversion. Loss aversion in riskless choice and loss aversion in risky choice are strongly positively correlated, but on average riskless loss aversion is higher than risky loss aversion. We find that in both choice tasks, loss aversion increases in age, income, and wealth, and decreases in education. Our results provide novel supportive input to the debate about the reality of loss aversion.
\end{abstract}

Keywords Loss aversion · Endowment effect - Reference-dependent preferences $\cdot$ Lab-in-the-field experiments

\section{Introduction}

Loss aversion-the psychological propensity that losses loom larger than equalsized gains relative to a reference point—can occur in riskless and in risky choices, as argued in two seminal papers by Amos Tversky and Daniel Kahneman (Kahneman \& Tversky, 1979; Tversky \& Kahneman, 1991). An example for loss

Simon Gächter

simon.gaechter@nottingham.ac.uk

1 School of Economics, University of Nottingham, Nottingham NG7 2RD, UK

2 CESifo, Poschingerstraße 5, 81679 Munich, Germany

3 Institute of Labour Economics, Schaumburg-Lippe-Straße 5-9, 53113 Bonn, Germany

4 Columbia Business School, 514 Uris Hall, New York, NY 10027, USA

5 Institut für Mobilität, University of St. Gallen, Bahnhofstrasse 8, 9000 St. Gallen, Switzerland 
aversion in riskless choice is the 'endowment effect' - the observation that experimental subjects who are randomly endowed with a commodity ask for a selling price that exceeds substantially the buying price of subjects, who merely have the possibility to buy the commodity (see Kahneman et al., (1990) for a very influential study and Ericson and Fuster (2014) for a survey). An example of loss aversion in risky choices is the observation that people reject small-scale gambles that have a positive expected value but may involve losses (e.g., Fehr \& Goette, 2007; Rabin, 2000; Tom et al., 2007; see Wakker, (2010), for a comprehensive review of models and empirical relationships). ${ }^{1}$

In this paper, we document loss aversion in a lab-in-the-field experiment with a large non-student sample (660 randomly selected customers of a car manufacturer) in (1) two riskless endowment effect experiments, and in a risky choice task. The riskless task is an endowment effect experiment where we elicit the 'willingness-toaccept' (WTA) and/or the 'willingness-to-purchase' (WTP). The gap between WTA and WTP has been interpreted as evidence for loss aversion in riskless choice (e.g., Rozin \& Royzman, 2001; Tversky \& Kahneman, 1991). We do these experiments in two versions: between subjects (Study 1; $n=300$ ) and within subjects (Study 2; $n=360$ ). The elicitation of both valuations from the same individual in Study 2 distinguishes us from previous literature that focused predominantly on aggregatelevel measures from between-subject designs. In these experiments (and in our Study 1), different respondents were asked either the WTA or the WTP question. Thus, unlike most of previous literature on the endowment effect, we can compare estimated loss aversion in between- and within-subjects experiments. The withinsubjects experiments also allow us to address the importance of individual differences in loss aversion because we can investigate individual, not only aggregate WTA-WTP gaps.

We report evidence for WTA/WTP $>1$ that is similar in the between- and within-subjects experiments (Result 1). Based on population averages of WTA and WTP, WTA/WTP between $=2.00$ and WTA/WTP $\mathrm{Within}=1.70$. This is our Result 2 . Result 3 reports estimates of individual-level loss aversion $\left(\lambda^{\text {riskless }}\right)$ based on an individual's WTA/WTP ratio. The estimated mean individual $\lambda^{\text {riskless }}=2.12$ and the median is $1.73 ; 82 \%$ of our participants are loss averse.

\footnotetext{
${ }^{1}$ Loss aversion has been invoked to explain many economic phenomena that are hard to understand under the assumption of reference-point independence. Prominent examples comprise behavior in financial markets (e.g., Benartzi \& Thaler, 1995; Haigh \& List, 2005; Odean, 1998); selling patterns in housing markets (Einiö et al., 2008; Genesove \& Mayer, 2001); coordination (Cachon \& Camerer, 1996); choice bracketing (Rabin \& Weizsäcker, 2009; Read et al., 1999); consumption behavior (Bowman et al., 1999; Heidhues \& Koszegi, 2008); medical decision making (Bleichrodt \& Pinto, 2002; Bleichrodt et al., 2007); marketing practices (Carmon \& Ariely, 2000; Hardie et al., 1993); trade policy (Freund \& Ozden, 2008; Tovar, 2009); labor supply (Camerer et al., 1997; Fehr \& Goette, 2007; Goette et al., 2004) and the importance of defaults and the status-quo bias in decision making (Samuelson and Zeckhauser (1988); Johnson and Goldstein (2003); Jachimowicz, et al. (2019)). Camerer (2004) provides an overview of the field evidence, and Starmer (2000) a survey of theoretical explanations. See Sugden (2003), Schmidt, et al. (2008), and Köszegi and Rabin (2006) for theoretical frameworks of reference-dependent preferences that can explain many of these phenomena. See O'Donoghue and Sprenger (2018) for a survey.
} 
The risky choice task consists of six simple low-stake lotteries with a 50-50 chance of a fixed gain of $€ 6$ and losses that vary from $€ 2$ to $€ 7$. Subjects must indicate for each of the six lotteries whether they want to play this lottery or not (in case they reject a lottery their payoff is zero). This lottery choice task arguably measures loss aversion in risky choices (e.g., following Rabin, 2000; Wakker, 2005). Subjects who reject lotteries with losses $€ 2$ to $€ 5$ are loss averse, which is the case for $71 \%$ of our subjects. The estimated median loss aversion $\lambda^{\text {risky }}=1.33$ (in our benchmark model). This is our Result 4. It suggests that the popular estimate of 2.25 of Tversky and Kahneman (1991) is probably too high.

Our within-subjects elicitation of $\lambda^{\text {riskless }}$ and $\lambda^{\text {risky }}$ allows for a test of whether they are correlated at individual level. There are strong theoretical considerations why these two measures should be correlated; if probability weighting is independent of utility, loss aversion should operate similarly in riskless and riskless choices. Moreover, neuroscientific analysis have suggested that loss aversion is encoded independently of risk (Tom et al., 2007).

However, there are also reasons that might suggest a limited correlation. The idea that preferences are constructed (see, e.g., the collection by Lichtenstein \& Slovic, 2006) challenges the hypothesis that we would see significant correlations across different ways of measuring loss aversion. For instance, numerous experiments have demonstrated that preferences differ across response modes. The endowment effect experiment involves two pricing tasks, while the lotteries involve a series of choice tasks. These two response modes are central to the classic demonstrations of preference reversals. It is plausible that they trigger different cues or different weighting schemes for the attributes (Tversky et al., 1988). Consistent with this, Chapman et al. (2017) find no correlation between the endowment effect (for a lottery) and loss aversion in risky choice. Second, research in psychology and experimental economics has shown that different measures of risk taking behavior are often not strongly correlated across different elicitation methods and domains (e.g., Crosetto \& Filippin, 2016; He et al., 2018; Johnson \& Schkade, 1989; Weber et al., 2002).

We find clear evidence for a correlation between $\lambda^{\text {riskless }}$ and $\lambda^{\text {risky }}$. The Spearman correlation is 0.677 and significant at any level. $\lambda^{\text {risky }}$ is lower than the estimated loss aversion $\lambda^{\text {riskless }}$. This is our Result 5 .

As a last step, we also examine the robustness of our findings by investigating the relationship between socio-demographic variables and loss aversion. In most studies, the experimental participants are undergraduates who share very similar socio-demographic backgrounds (exceptions are, e.g., Booij \& Van De Kuilen, 2009; Dohmen et al., 2011; Kovalchik et al., 2005; Li et al., 2013, 2015). Using undergraduates precludes inferences about how socio-demographic variables affect loss aversion. By contrast, the participants of our experiments are a random sample of 660 customers of a German car manufacturer. ${ }^{2}$ Our subjects comprise a large age, education, income, and wealth spectrum. Of course, car customers may not be

\footnotetext{
2 The experiments were part of a survey on motives to buy a car and on hypothetical valuations for certain product attributes of a car aimed at evaluating loss aversion for car attribute endowments (see our companion paper Mrkva et al. (2020) for the details).
} 
representative for the population at large, but we can answer how in our sample socio-demographic variables affect loss aversion both in riskless and in risky choices. In Result 6, we show that the socio-demographic variables affect both measures of loss aversion similarly. Loss aversion is positively correlated with age, wealth and income, and negatively correlated with education. We find no significant gender differences in loss aversion.

Our data and results provide novel input into a debate about whether loss aversion is a real phenomenon (Ert \& Erev, 2013; Gal, 2006; Gal \& Rucker, 2018; Plott \& Zeiler, 2005; Yechiam, 2019), which some even called a "fallacy" (Gal, 2018). We will address some of the criticisms in our discussion section. We also refer the reader to our companion paper (Mrkva et al., 2020), which uses the withinsubject data of this paper plus a host of new survey experiments intended to measure moderators of loss aversion. Taken together, this paper, and Mrkva et al. (2020), provide strong evidence for the empirical relevance of loss aversion, while acknowledging that loss aversion has important moderators.

\section{Methods}

In total, 660 randomly selected customers of a large German car manufacturer participated in our two studies. All participants are German speaking and live in Austria, Germany, and Switzerland. The data were collected in collaboration with a market research company. Data collection was done in personal interviews in 30 Austrian, German, and Swiss municipalities. The interviews took place at the respondent's home or at the local car dealer. All our subjects had recently bought a car from this manufacturer. The subjects were randomly selected from an address file and recruited by telephone for a study on motives of buying a particular type of car. To cover their opportunity costs of participation and to induce them to participate at all, every subject received a flat payment of $€ 50$. In addition to this, we paid participants according to their decisions in the experiments.

Twelve professional interviewers collected the data. They all received extensive training to familiarize them with the research design. Each respondent was always alone with an interviewer, undisturbed by car dealers or other customers. The experiment was embedded in this market research interview that lasted about $1 \mathrm{~h}$. While familiar with the experimental protocol, all interviewers were naïve about the experimental hypotheses.

We conducted two studies, which involved two separate sets of participants. Both studies involved the elicitation of WTA and WTP of a toy car model from this manufacturer. The aim of Study 1 was to replicate procedures and results of previous WTA-WTP studies in a between-subjects design. The novelty of this benchmark study is to provide a measure of aggregate loss aversion, derived from the WTA-WTP disparity in a large non-student subject pool (300 customers of this manufacturer). This benchmark is important given the fact that our research did not take place in a laboratory, and to ensure the comparability of our within-subject estimates of loss aversion to the usual between-subject measures. The goal of Study 2 was to measure loss aversion at the individual level in a within-subject design. We 
complement our individual measure of loss aversion in riskless choice with one from a risky choice task, to answer the question whether these measures are correlated. All subjects who participated in the within-subject design study also took part in the lottery choice task.

In Study 1, half of the respondents were randomly assigned to the WTA valuation task and the other half to the WTP task. Our procedure is similar to most previous experiments on WTA and WTP elicitation tasks. We adapted the procedure by Kahneman et al. (1990)), who used coffee mugs for their evaluation task, for our purposes.

Specifically, subjects in the WTA valuation task were given a miniature model car and told that it was theirs. They were then asked to specify the price at which they would be willing to sell the car to the organizers of the scientific study. Subjects were shown a list of prices, varying from $€ 0$ to $€ 10$, with $€ 0.50$ increments. ${ }^{3}$ For each of the prices they had to indicate whether they wanted to sell or not to sell their model car at this price. The format of each of the choices was as follows:

To give subjects an incentive to report their true valuation, we applied the Becker-deGroot-Marschak mechanism (Becker et al., 1964). After subjects had made their choice for all potential prices, a price was determined randomly. If the randomly selected price was one for which the respondent had indicated that they would sell the toy car, the model car was returned to the experimenter and the randomly determined price in cash was given to the respondent. If the respondent indicated that the chosen price was one at which they were not prepared to sell, they kept the model car. The respondents were aware of this procedure.

The procedures for the respondents in the WTP valuation task were identical, except that they were not endowed with a toy car. Instead, they were shown a toy car and told that it could be theirs. They had to indicate for each of the prices between $€ 0$ and $€ 10$ whether they were prepared or not to buy at that price. Again, a random device determined the offered price and the indicated choice for that price was implemented accordingly. The exact wording of the valuation task is documented in the appendix.

The results from Study 1 can be used to measure aggregate-level loss aversion. If we replicate with our subject pool and procedures the results from similar previous experiments, we should, on average, find a positive WTA-WTP difference. Such a difference has been interpreted as evidence for loss aversion (Bateman et al., 1997; Kahneman et al., 1990, 1991; Novemsky \& Kahneman, 2005; Rozin \& Royzma,

\footnotetext{
${ }^{3}$ We chose the range $€ 0$ to $€ 10$ because the market value of such toy cars was in this range. Indeed, only three participants were willing to pay $€ 10$ for getting the toy car.
} 
2001; Tversky \& Kahneman, 1991), although other interpretations exist as well (see, e.g., Morewedge \& Giblin, 2015 for a survey). ${ }^{4}$

Our Study 2 involved 360 randomly selected customers of the same car manufacturer who all had not participated in Study 1. Here, the WTA and WTP valuation experiments were well integrated into a larger survey study (for the details of this survey study see our companion paper Mrkva et al., 2020). The purpose of our second study is to use the same procedures to measure individual-level loss aversion. If an individual's relative value of WTA and WTP is a useful measure of individual-level loss aversion, then we must obtain both WTA and WTP from each respondent. Therefore, respondents now answered both the WTA and the WTP valuation task. Thus, we have a within-subject design. ${ }^{5}$

Subjects were informed that we randomly assigned them a model car or not, and that an envelope containing their status as buyers or sellers would be opened at the end of the study. We applied the strategy method by asking the subjects to give us both their WTA in the case that they would own the model car and their WTP in the case they would not own it. Subjects were told that one of the transactions would occur, depending upon whether the envelope assigned them to the buyer or seller role. The order in which a particular respondent answered the two tasks was randomly determined. Half of the subjects started with the WTA valuation task, followed by the WTP valuation task; for the other half the order was reversed. The valuation tasks were separated by several market research survey questions related to the features of cars.

We used the same questionnaire and procedures as in the between-subjects study, but adapted the explanation to our within-subject design. For instance, if a participant started with the WTA task, he or she was told to make the decisions for the case that he or she would own this toy car. Later in the survey, the participants were confronted with the WTP task and asked to make their choices in case they would not own this toy car but were instead given the possibility to buy it. Again, they were told that whether they would own the toy car or would be given the opportunity to buy it would be determined randomly at the end of the study. Thus, our application of the strategy method to the WTA and WTP evaluation task allows us to obtain within-respondent estimates of loss aversion.

The potential drawback of this within-subject elicitation procedure is that the answer on the first task may influence the answer on the second one. Therefore, the WTA and WTP results from the between-subjects elicitation of our first benchmark study serve as an important control.

\footnotetext{
4 Alternative explanations as surveyed in Morewedge and Giblin (2015) include evolutionary advantage in bargaining (e.g., Huck et al., 2005); strategic misrepresentation (e.g., Plott \& Zeiler, 2005); reference price theory (e.g., Weaver \& Frederick, 2012); and biased information processing (e.g., Johnson et al., 2007).

5 All previous endowment effect studies with riskless choice we are aware of used a between-subject design (akin to our benchmark study). There are only a few studies which employ a within-subject design for eliciting WTA and WTP for lotteries. Examples include Harless (1989); Kachelmeier and Shehata (1992); Eisenberger and Weber (1995) and Chapman et al. (2017). See also Loewenstein and Adler (1995) and Bibby and Ferguson (2011) for designs related to ours.
} 
Our second goal is to measure loss aversion in risky choices. For that purpose, we adapt a simple lottery choice task from Fehr and Goette (2007) that arguably measures loss aversion as well (see also Bibby \& Ferguson, 2011 for a similar task). In this choice task, individuals decide for each of six lotteries whether they want to accept (that is, play it) or reject it (and receive nothing). In each lottery, the winning price is fixed at $€ 6$ and only the losing price is varied (between $€ 2$ and $€ 7$ ). At the end of the experiment, we randomly selected one lottery for pay (Cubitt et al., 1998). Figure 1 reproduces the decision sheet of the lottery choice task as presented to subjects (translated from German).

Arguments put forward by Rabin (2000), Schmidt and Zank (2005), Wakker (2005), Köbberling and Wakker (2005) and Fehr and Goette (2007) suggest that the lottery choice task measures loss aversion rather than risk aversion (utility curvature). Rabin (2000), for instance, argues that utility curvature cannot plausibly explain choice behavior in small-stake risky prospects like ours. A concave utilityof-wealth function in such small-stake lotteries would imply absurd degrees of risk aversion in high-stake gambles. Therefore, Rabin (2000) argues that under EU, people in such gambles should be risk neutral. In our risky choice task, people should therefore accept lotteries \#1 to \#5, which all have a non-negative expected value. If we nevertheless observe rejections of low-stake gambles with a positive expected value, then this might indicate loss aversion rather than risk aversion. This interpretation would certainly be vindicated if choice behavior in the lottery task would be correlated with the WTA-WTP gap as measured in the riskless valuation task.

Furthermore, the expected values of the 50-50 gambles we use (Fig. 1) are easy to calculate; the lotteries vary in attractiveness; and the status quo is not playing the gamble. As Ert and Erev (2013) have shown, these design features favor the observation of loss aversion. By contrast, as Ert and Erev (2013) have also shown, loss-averse choices are more likely with high payoffs than with the low payoffs that

\begin{tabular}{|c|c|c|}
\hline & $\begin{array}{l}\text { I don't } \\
\text { want to } \\
\text { toss the } \\
\text { coin }\end{array}$ & $\begin{array}{l}\text { I want to } \\
\text { toss the coin }\end{array}$ \\
\hline 1. If the coin turns up heads, then you lose $€ 2$; if the coin turns up tails, you win $€ \mathbf{6}$. & $\mathrm{O}$ & $\mathrm{O}$ \\
\hline 2. If the coin turns up heads, then you lose $€ \mathbf{3}$; if the coin turns up tails, you win $€ \mathbf{6}$. & $\mathrm{O}$ & $\mathrm{O}$ \\
\hline 3. If the coin turns up heads, then you lose $\boldsymbol{€ 4}$; if the coin turns up tails, you win $€ \mathbf{6}$. & $\mathrm{O}$ & $\mathrm{O}$ \\
\hline 4. If the coin turns up heads, then you lose $\mathbf{€ 5}$; if the coin turns up tails, you win $€ \mathbf{6}$. & $\mathrm{O}$ & $\mathrm{O}$ \\
\hline 5. If the coin turns up heads, then you lose $\boldsymbol{€ 6}$; if the coin turns up tails, you win $€ \mathbf{6}$. & $\mathrm{O}$ & $\mathrm{O}$ \\
\hline 6. If the coin turns up heads, then you lose $€ 7$; if the coin turns up tails, you win $€ 6$. & $\mathrm{O}$ & $\mathrm{O}$ \\
\hline
\end{tabular}

Fig. 1 The lottery choice task 
we use. However, rejection of lotteries with non-negative payoffs under high stakes might reflect risk aversion rather than loss aversion. Therefore, our lotteries provide a conservative measure of loss aversion.

We can determine loss aversion in the risky choice task by applying cumulative prospect theory (Tversky \& Kahneman, 1992). A decision maker will be indifferent between accepting and rejecting the lottery if $w^{+}(0.5) v(G)=w^{-}(0.5) \lambda^{\text {risky }} v(L)$, where $L$ denotes the loss in a given lottery and $G$ the gain; $v(x)$ is the utility of the outcome $x \in\{G, L\}, \lambda^{\text {risky }}$ denotes the coefficient of loss aversion in the risky choice task; and $w^{+}(0.5)$ and $w^{-}(0.5)$ denote the probability weights for the 0.5 chance of gaining $G$ or losing $L$, respectively. If we assume that the same weighting function is used for gains and losses, $w^{+}=w^{-}$(see Prelec, 1998, Eq. (3.1), p. 503), only the ratio $v(G) / v(L)=\lambda^{\text {risky }}$ defines an individual's implied loss aversion in the lottery choice task. A frequent assumption on $v(x)$ is linearity $(v(x)=x)$ for small amounts, which gives us a very simple measure of loss aversion: $\lambda^{\text {risky }}=G / L$. We later relax some of these assumptions because there is evidence that $w^{+} \neq w^{-}$ (Abdellaoui, 2000).

\section{Results}

We will first compare the valuations from our within- and between-subjects designs in our riskless choice task. Our second step will then be to describe the heterogeneity in individual-level loss aversion. Our third and fourth steps examine loss aversion in a risky choice task and its relationship to loss aversion in riskless choice. Finally, we will look at the impact of socio-demographic characteristics on loss aversion.

\subsection{Eliciting WTA and WTP between and within subjects}

Result 1: The method of eliciting WTA and WTP from the same person in our withinsubject design did not change the answers systematically relative to a betweensubjects control in which respondents only answered either a WTA question or a WTP question.

Support: Figure 2 provides the main support for Result 1. It shows the cumulative frequency distributions of the elicited WTA and WTP measures. We identify WTA as the midpoint between the price at which a seller is willing to sell and the nextlowest price at which they are not willing to sell. Similarly, WTP is the midpoint between the price at which a buyer is willing to buy and the next-highest price at which they are not willing to buy. ${ }^{6}$ We distinguish whether the respective measure is elicited from another participant of the study ("between-subject"-Study 1) or from the same person ("within-subject" —Study 2).

We find only small differences between the elicited values in Study 1 and Study 2. In the WTP valuation problems, the mean elicited WTP in the between-subjects

\footnotetext{
${ }^{6}$ For this analysis, we discard the observations from subjects who submitted non-monotonic valuations (10\% in the between-subjects elicitation mode of Study 1 and $10.3 \%$ in the within-subjects elicitation mode of Study 2).
} 


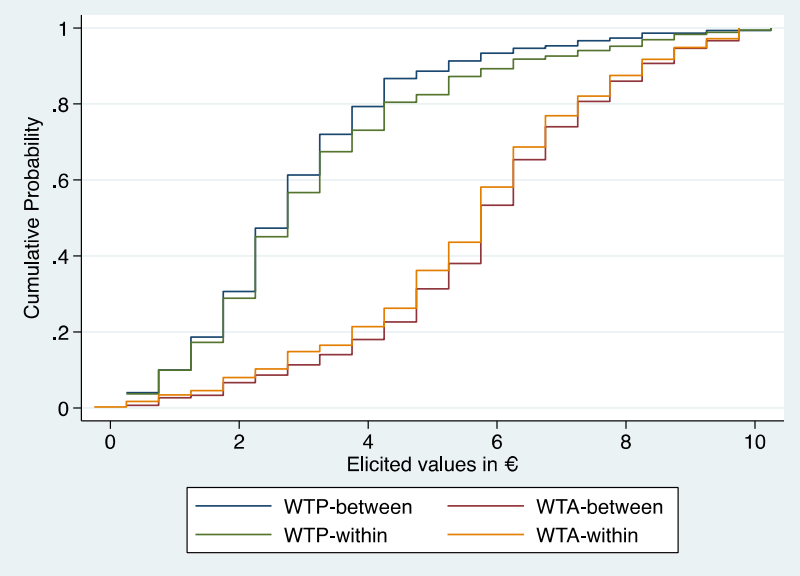

Fig. 2 Cumulative distribution of elicited values of WTA and WTP $\mathrm{n}$ the within- and between-subjects design

mode of Study 1 is $€ 2.89$, versus $€ 3.21$ in the within-subject mode of Study 2 . For WTA we find slightly higher values in the between-subjects mode than in the within-subjects mode (€5.79 vs. €5.52). Yet, Kolmogorov-Smirnov tests (which compare distribution functions and not only means) find that the differences are very small and not significant $(p>0.67)$.

Next, we check for sequence effects in the within-subject design. We do this in two ways. First, we compare whether WTA and WTP depend on whether WTA (or WTP) came first or second (i.e., we compare $\mathrm{WTA}_{\text {first }}=\mathrm{WTA}_{\text {second }}$; and $\left.\mathrm{WTP}_{\text {first }}=\mathrm{WTP}_{\text {second }}\right)$. We find no significant sequence effect of our within-subject elicitation in either WTA or WTP ( $p>0.67$, Kolmogorov-Smirnov tests). Second, we can compare the second stage measures, whether they be WTA or WTP to the same measure in our between-subjects study, where respondents only answered a single question. Kolmogorov-Smirnov tests do not find any differences. The WTA of the participants of our between-subjects study is not significantly different from the potentially biased WTA of the participants of our within-subjects study who answered WTA after WTP $(p=0.492)$. A similar conclusion holds for WTP $(p=0.425)$. We also ran an OLS regression (with robust standard errors clustered on subjects), pooling data from Study 1 and Study 2, that confirms that WTA and WTP are significantly different $(p<0.0001)$, but that there was no difference due to sequence $(p>0.15)$.

\subsection{Loss aversion in riskless choice}

Our next result documents the aggregate-level WTA-WTP disparity, which has often been interpreted as loss aversion in riskless choice.

Result 2: There is a large difference between WTA and WTP. The ratio $(\operatorname{mean}(W T A) / \text { mean }(W T P))_{\text {between }}=2.00$, and the ratio $($ mean $(W T A) /$ $\operatorname{mean}(W T P))_{\text {within }}=1.70$. 
Support: In the between-subjects elicitation mode (Study 1), the mean WTA is $€ 5.79$ (median 5.75), whereas the mean WTP value is $€ 2.89$ (median 2.75). The WTA-WTP difference is highly significant according to both a two-sided $t$ test $(p<0.001)$ and a Kolmogorov-Smirnov test $(p<0.0001)$. The elicited mean values imply a WTA/WTP ratio of 5.79/2.89 = 2.00 and, based on median values, a WTA/WTP ratio of 5.75/2.75 $=2.09$.

In the within-subject elicitation mode (Study 2), the mean WTA is $€ 5.50$ and the mean WTP is €3.24; the median WTA (WTP) is 5.75 (2.75). Because the same person answered both valuation problems, we applied a matched-pairs $t$ test. The difference between WTA and WTP is significant at all conventional levels $(p<0.0001)$. Thus, the overall WTA/WTP ratio based on overall means is 5.50/ $3.24=1.70$. Based on medians, the overall WTA/WTP ratio is 5.75/2.75 $=2.09$.

Is the WTA/WTP ratio of the Study 1 within-subjects elicitation significantly different from the Study 2 between-subjects elicitation? In the between-subjects elicitation, we can only calculate a benchmark number for the Study 1 participants as a whole, whereas in Study 2 we have WTA/WTP ratios for each individual with WTP $>0$. We therefore ran a one-sample $t$ test to see whether the individual WTA/ WTP ratios of Study 2 are significantly different from $\mathrm{WTA} / \mathrm{WTP}_{\text {between }}=2.0$. The test does not reject the null hypothesis of no difference $(t=1.354, p=0.177)$.

Result 2 is in line with previous findings of studies which also elicited betweensubject WTAs and WTPs (see Kahneman et al., 1990, Table 1). Kahneman et al. find WTA/WTP relations of 2.21 in their mug experiments (Table 2). Knetsch (1989)) reports a WTA/WTP relation of 2.09. See Horowitz and McConnell (2002), Sayman and Onculer (2005); and Tunçel and Hammitt (2014) for reviews. We conclude that our elicitation methods lead to results that are highly regular and consistent with previous findings from the laboratory.

Our next result concerns the individual-level differences in the WTA/WTP ratios of Study 2. Figure 3 depicts the distribution (kernel density) of the individual WTA/ WTP ratios.

We interpret an individual's WTA/WTP ratio as a measure of loss aversion. We denote the WTA/WTP ratio as $\lambda^{\text {riskless }}$ to distinguish it from a risky measure of loss aversion introduced above. If an individual is not loss averse, then their WTA should equal their WTP, that is, WTA/WTP $\equiv \lambda^{\text {riskless }}=1$. For a loss-averse individual, it holds that WTA $>$ WTP, that is, $\lambda^{\text {riskless }}>1$, for WTP $>0$. Out of the 323 respondents with monotonic evaluations, 310 individuals (that is $96 \%$ ) report a WTP $>0$.

Result 3: 82\% of individuals display loss aversion in riskless choice, that is, their $\lambda^{\text {riskless }} \equiv W T A / W T P>1$. The mean $\lambda^{\text {riskless }}$ is 2.12 and the median $\lambda^{\text {riskless }}$ is 1.73 . The interquartile range is $[1.21,2.56]$. The standard deviation is 1.52 .

Support: We find that $11.6 \%$ of our participants report $\lambda^{\text {riskless }}<1$, that is, they report WTA $<$ WTP. For $6.13 \% \lambda^{\text {riskless }}=1$, as would be predicted by the standard economic argument that the reference point should not matter for the elicitation of reservation prices (neglecting income effects). For 255 out of 310 respondents $(\approx$ $82 \%), \lambda^{\text {riskless }}>1$, that is, these individuals show some degree of loss aversion. $7 \%$ of them are very strongly loss averse in the sense that their $\lambda^{\text {riskless }}>4$; the highest $\lambda^{\text {riskless }}$ is 11 . If we only classify, conservatively and somewhat arbitrarily, those 


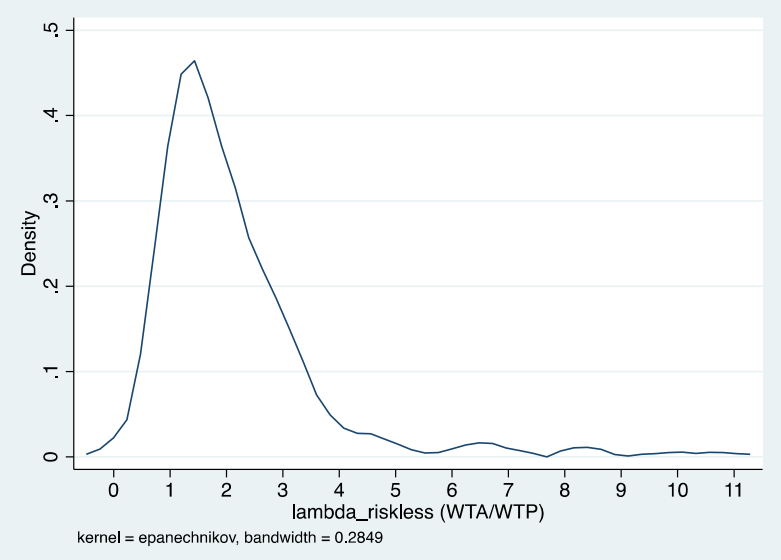

Fig. 3 The distribution of individual WTA/WTP-ratios $\left(\lambda^{\text {riskless }}\right)$

individuals as loss averse for whom WTA/WTP is "too big" (>1.2) from a standard view plus errors perspective, we find that $76.4 \%$ of the respondents are loss averse.

Our analysis neglects diminishing sensitivity as assumed in prospect theory. We believe this is justified given the small stakes involved in our experiment and the findings in an experiment with comparable stakes by Fehr-Duda et al. (2006) who show that the vast majority of their subjects exhibit linear value functions. When we nevertheless incorporate diminishing sensitivity and assume a power utility function $v(x)=x^{\alpha}, 0<\alpha<1$ (see Wakker, 2008) for a discussion), the observed mean individual $\lambda^{\text {riskless }}$ is reduced. If we use the $\alpha=0.88$ estimate by Tversky and Kahneman (1992), the mean [median] individual $\lambda^{\text {riskless }}=1.90$ [1.62]. More recent estimates by Booij and Van De Kuilen (2009), who have data from a large representative subject pool most comparable to ours, suggest values of $\alpha$ around 0.95 . In the latter case, the mean [median] $\lambda^{\text {riskless }}=2.03[1.68]{ }^{7}$

A complementary way to measure loss aversion is to test for a positive correlation between WTA and WTP, because, under loss aversion, WTA $=\lambda^{\text {risk- }}$

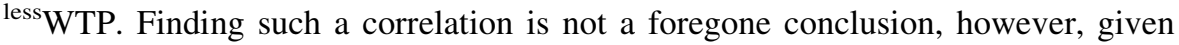
that Chapman et al. (2017) found an endowment effect (that is, a WTA-WTP gap (for lotteries)), but only a weak correlation between WTA and WTP. A simple robust OLS regression reveals a highly significantly positive correlation of WTA and WTP in our data set $\left(\mathrm{WTA}=3.66(0.21)+0.57(0.04) \mathrm{WTP}, R^{2}=0.31\right)$. This corroborates our interpretation of $\lambda^{\text {riskless }}$ as measuring loss aversion.

\footnotetext{
${ }^{7}$ While desirable, our data does not allow individual-level estimations of $\alpha$. See Schmidt et al. (2008); Abdellaoui et al. (2007); Harrison and Rutström (2009); and Bruhin et al. (2010) for further plausible $\alpha$ values.
} 


\subsection{Loss aversion in risky choice}

Our third step is to look at loss aversion in risky choices. Recall that in our lottery choice task in general, $\lambda^{\text {risky }}=\left(w^{+}(0.5) / w^{-}(0.5)\right)(v(G) / v(L))$. As for $\lambda^{\text {riskless }}$, we only consider monotonic acceptance decisions (326 of $360 \approx 91 \%$ of subjects display monotonicity).

Result 4: 71\% of our subjects display some loss aversion in risky choice, that is, their $\lambda^{\text {risky }}>1$. The median estimated $\lambda^{\text {risky }}=1.33$ in our benchmark model.

Support: Table 1 records the results of four different assumptions on probability weights and diminishing sensitivities for gains and losses. We assume the maximally acceptable loss is the midpoint in switching from accept to reject in Fig. 1 . We also report the benchmark $\lambda_{\max }^{\text {risky }}$, which is derived from the loss of the last lottery accepted before switching to reject and assuming no probability weighting and no diminishing sensitivity.

The rationale of the four models is to vary assumptions on probability weighting and diminishing sensitivities for gains and losses systematically to see their differential impact on implied levels of loss aversion. The benchmark case (model (a)) is that both probability weighting and diminishing sensitivity are unimportant. Model $(b)$ assumes that differential probability weighting for gains and losses is unimportant (that is, $\left.w^{+}(0.5) / w^{-}(0.5)=1\right)$, but allows for diminishing sensitivities for gains and losses (we take the median estimates of Booij \& Van De Kuilen, 2009). Model (c) assumes diminishing sensitivity is unimportant, but allows for differences in probability weights for gains and losses. We take the estimates of Abdellaoui (2000), Table 9, who reports that $w^{+}(0.5)=0.394$ and $w^{-}(0.5)=0.456$ for the median individual, which is one of the largest differences between $w^{+}(0.5)$ and $w^{-}(0.5)$ found in the literature (implying $\left.w^{+}(0.5) / w^{-}(0.5)=0.86\right){ }^{8}$ It therefore provides an upper bound for the importance of differential probability weightings of gains and losses for the median individual in our context. Model $(d)$ assumes that both probability weighting and diminishing sensitivities matter.

According to Table 1, 12.6\% accepted all lotteries with a non-negative expected value and only rejected lottery \#6, which has a negative expected value. Hence, according to the benchmark model $(a)$, their implied $\lambda^{\text {risky }}=1$. Slightly more than $16 \%$ of our respondents also accepted lottery \#6, which has a negative expected value, that is, in model $(a)$ their $\lambda^{\text {risky }} \leq 0.86$. Most participants rejected gambles with a positive expected value. Specifically, $70.9 \%$ of our respondents rejected at least lottery \#5 or already some lottery \#1 to \#4; about $17.8 \%$ of respondents reject lotteries that give them a non-positive expected value. A few respondents (1.8\%) rejected all six lotteries; for these people, $\lambda^{\text {risky }}>3$. The median respondent's cutoff lottery was \#4: he or she accepted lotteries \#1 to \#4 and rejected lotteries \#5 and \#6, which in the benchmark model implies $\lambda^{\text {risky }}=1.33$. The various assumptions on

\footnotetext{
${ }^{8}$ See Bleichrodt and Pinto (2000), Table 1 for a summary of parameter estimates reported in the earlier literature. For instance, for the weighting function proposed by Tversky and Kahneman (1992)), estimated parameters imply $w^{+}(0.5) / w^{-}(0.5)=0.933$. Fehr-Duda et al. (2006)) report $w^{+}(0.5) / w^{-}(0.5)$ between 0.91 and 0.964 (calculated from their data in Table III). The estimates in Bruhin et al. (2010), Table IX) range from 0.82 to 1.04 . Abdellaoui et al. (2008) cannot reject that $w^{+}(0.5) / w^{-}(0.5)=1$ in their data.
} 
Table 1 Acceptance rates of the different lotteries in the lottery choice task and implied $\lambda^{\text {risky }}=\omega^{*}\left(6^{\alpha} /\right.$ $\left.L^{\beta}\right), \omega \equiv w^{+}(0.5) / w^{-}(0.5)$

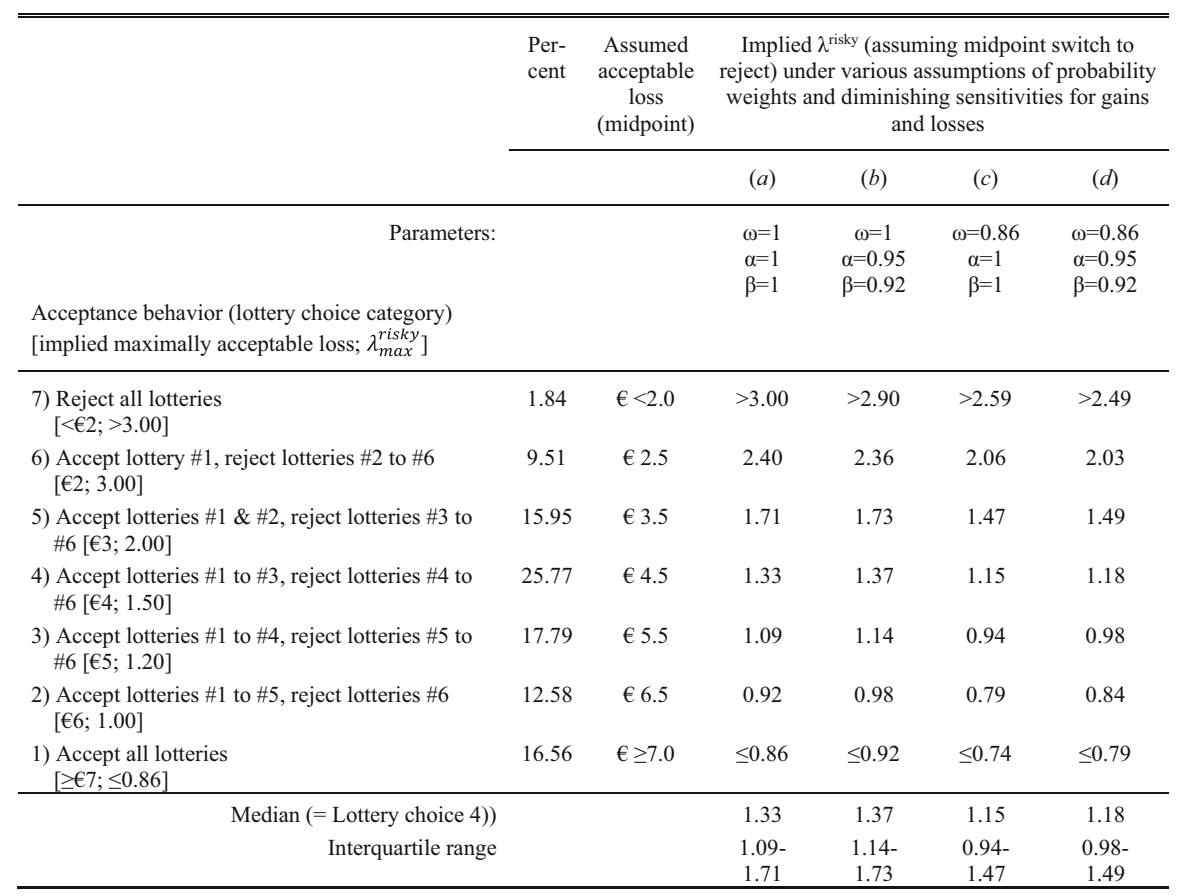

(a) Benchmark parameters: no probability weighting, and no diminishing sensitivity, (b) No probability weighting but diminishing sensitivity, (c) Probability weighting, but no diminishing sensitivity, (d) Probability weighting and diminishing sensitivity. Parameters on diminishing sensitivity taken from Booij and Van De Kuilen (2009); parameters on $\omega$ taken from Abdellaoui (2000). Only subjects with monotonic preferences are included $(n=326)$. $\lambda_{\text {max }}^{\text {risky }}$ assumes model assumptions $(a)$; the median is $1.50 ; \mathrm{IQR}=$ 1.2-2.0. We report median and the interquartile range because for lottery choice categories 1) and 7) loss aversion is not uniquely identifiable. This leaves 266 participants with a well-defined $\lambda^{\text {risky }}$

probability weighting and diminishing sensitivity change the values of implied $\lambda^{\text {risky }}$. However, the median individual is loss averse according to all four models.

\subsection{Correlation of loss aversion in riskless and risky choice}

Result 5: $\lambda^{\text {riskless }}$ is significantly positively correlated with the switch point in the lottery choice task. Hence, the implied levels of loss aversion are positively correlated. The implied levels of $\lambda^{\text {risky }}$ are lower than those of $\lambda^{\text {riskless }}$.

Support: Fig. 4 illustrates Result 5. Shown is a scatter plot of respective values of $\lambda^{\text {riskless }}$ as defined in Sect. 3.2 and the switch point in the lottery choice task (see Fig. 1), where higher values imply a higher level of $\lambda^{\text {risky }}$; exact levels depend on model assumptions (see Table 1). The table in Fig. 4 illustrates an upper bound for 
loss aversion, $\lambda_{\max }^{\text {risky }}$ (defined in Table 1). The line is a non-parametric lowess estimator.

Figure 4 shows that $\lambda^{\text {riskless }}$ and the switch point in the lottery choice task are positively correlated. For instance, individuals who accepted all lotteries (lottery choice category 1 in Fig. 4) have an $\lambda_{\max }^{\text {risky }}<0.86$ and a $\lambda^{\text {riskless }}=1.05$ on average. The median individual selected lottery choice is category 4 , which implies a $\lambda_{\max }^{\text {risky }}=1.50$; these individuals have an average $\lambda^{\text {riskless }}=2.18$. Individuals who reject all lotteries and therefore have a $\lambda_{\max }^{\text {risk }}>3$ have an average $\lambda^{\text {riskless }}=6.22$ (these are only six people, however). A Spearman rank order correlation between the two measures confirms the relationship observed in Fig. 4 (Spearman's $\rho=0.677 ; p<0.0001 ; n=281$ ). This also holds if we exclude the six 'outliers' with a $\lambda_{\max }^{\text {risky }}>3$. A regression analysis confirms this conclusion.

Thus, Fig. 4 provides evidence that loss aversion in riskless choice and loss aversion in risky choices are positively correlated at the individual level. Notice that the fact that $\lambda^{\text {riskless }}$ and $\lambda^{\text {risky }}$ are correlated does not depend on whether one believes in the exact value of $\lambda^{\text {riskless }}$ or $\lambda^{\text {risky }}$ as we have determined them in Table 1 as measures of loss aversion. The correlation simply confirms that a subject's WTA/WTP ratio and their acceptance behavior in the lottery choice task are significantly related.

Although $\lambda^{\text {riskless }}$ and $\lambda^{\text {risky }}$ are positively correlated, their values are not the same. The table in Fig. 1 illustrates this for an upper bound of loss aversion, $\lambda_{\max }^{\text {risk }}$. $\lambda^{\text {riskless }}$ exceeds $\lambda_{\max }^{\text {risky }}$ for all levels of $\lambda_{\max }^{\text {risky }}$. Why this is the case is a task left for future research. One possibility is that $\lambda^{\text {risky }}$ which involves choices, measures only loss aversion for money, and there is evidence that loss aversion for money is lower than that for commodities (Novemsky \& Kahneman, 2005); the extent is debated, however (Bateman et al., 2005). Because it uses a tradeoff, $\lambda^{\text {riskless }}$ reflects loss aversion for both money and the model car. Another possibility is that there is an emotional attachment to the car, a factor that increases loss aversion (Sokol-Hessner et al., 2009).

Three remarks are in order in interpreting Result 5. First, if the often-noted WTA-WTP disparity were largely due to subject misconception of the task then there would be no reason why $\lambda^{\text {riskless }}$ and $\lambda^{\text {risky }}$ are positively correlated. Second, in our view, the positive correlation provides convergent evidence for loss aversion. If we assume that the lottery choice task reveals loss aversion, then the fact that $\lambda^{\text {riskless }}$ and $\lambda^{\text {risky }}$ are positively correlated reinforces the interpretation that the endowment effect is due to loss aversion. A similar argument holds vice versa. Our results are in contrast to Chapman et al. (2017) who find no correlation. A reason for this might be that they elicit WTA and WTP for lotteries, whereas we elicit them for a commodity (a model toy car). Third, we note that this relationship is observed across two different response modes, suggesting that the underlying construct of loss aversion account exists across both a pair of judgment tasks (WTA and WTP) and a risky choice task. 


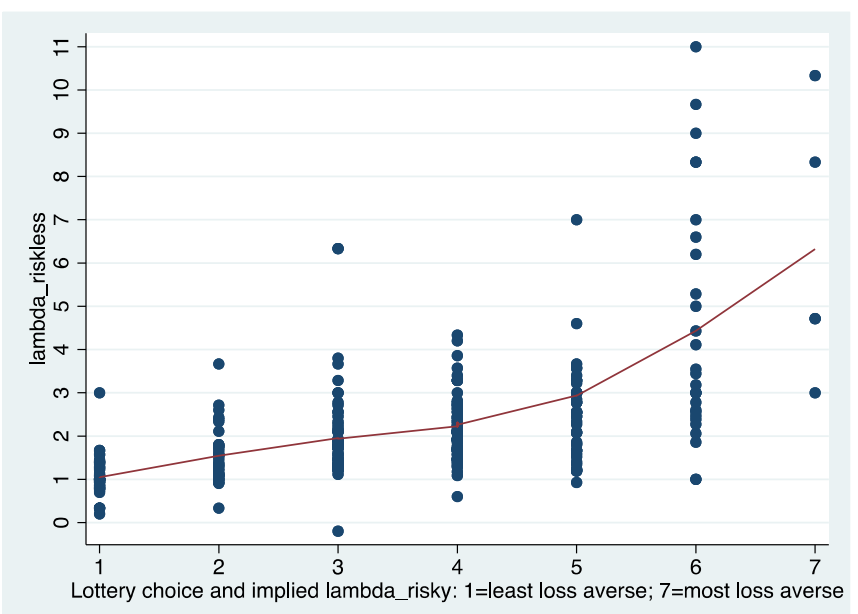

\begin{tabular}{|c|c|c|c|c|c|c|c|}
\hline Lottery & 1 & 2 & 3 & 4 & 5 & 6 & 7 \\
\hline$\lambda_{\text {max }}^{\text {risky }}$ & $\leq 0.86$ & 1.00 & 1.20 & 1.50 & 2.00 & 3.00 & $>3.00$ \\
\hline$\lambda^{\text {riskless }}$ & 1.05 & 1.48 & 2.03 & 2.18 & 2.51 & 4.37 & 6.22 \\
\hline
\end{tabular}

Fig. 4 Relationship between loss aversion in risky and riskless choice. Shown is a scatter plot of switch point in lottery choice task ("Lottery") and corresponding value of $\lambda^{\text {riskless. The line indicates a lowess }}$ estimator. The table reports an upper bound of loss aversion, $\lambda_{\max }^{\text {risky }}$, as implied by the lottery choice category. Alternative values of $\lambda^{\text {risky }}$ are in Table $1 . \lambda^{\text {riskless }}$ is the average riskless loss aversion for people in each lottery choice category

\subsection{Socio-demographics and loss aversion}

The final step in our analysis concerns the impact of socio-demographic factors on loss aversion. Since our subject pool is only representative of one group of customers but not for the population at large, we see this analysis mainly as robustness check whether the socio-demographic background of our subjects affects the two measures of loss aversion similarly. ${ }^{9}$

Figure 5 gives a first impression of the link between socio-economic variables and loss aversion by plotting the bi-variate relationships between the mean WTA/ WTP ratio as a measure of riskless loss aversion and the mean lottery choice category (see Table 1) as an indicator of loss aversion in risky choices. For both variables, higher values indicate more loss aversion. We look at six economically interesting variables: gender (panel A); age (panel B); household income (panel C); household wealth (panel D); education (panel E) and occupation (panel F).

Figure 5 reveals several observations. First, the qualitative patterns of both measures of loss aversion are very similar in all six panels. Second, we find a small but significant gender gap in both measures (panel A). According to both measures,

\footnotetext{
9 Booij and Van De Kuilen (2009) report experiments with a representative sample from the Dutch population. The gender and education effects we report below are consistent with their findings.
} 

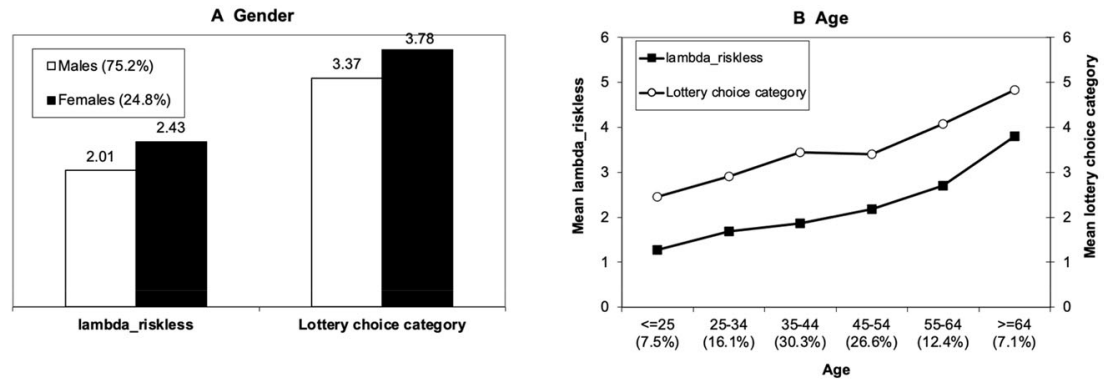

C Household income
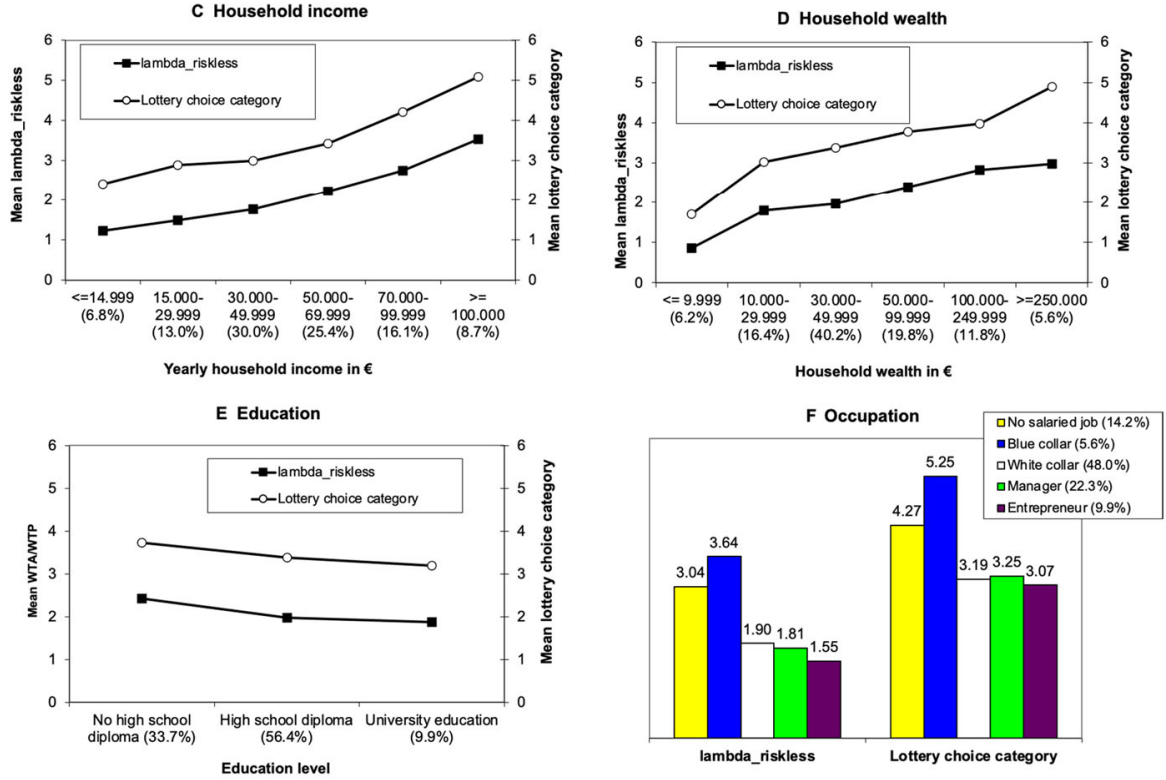

Fig. 5 Bivariate relation between socio-economic variables and indicators of loss aversion. A Lottery choice category (higher values indicate more loss aversion): see Table 1 how the categories map onto $\lambda^{\text {risky }}$ values. Because $\lambda^{\text {risky }}$ is not uniquely defined for lottery choice categories 1 and 7 , the figure illustrates the lottery choice categories and not $\lambda^{\text {risky }}$. B-F Percentages indicate the fraction of participants in a particular socio-economic category

females are on average more loss averse than males. This gender gap is supported by two-sided Mann-Whitney tests, which return $p<0.05$ for both measures.

Third, as panel B shows, older people tend to be more loss averse in both their riskless valuations and in their risky choices (Spearman rank order correlations, $p<0.0001)$. Fourth, the higher the household income, the higher is loss aversion (panel C). A similar conclusion holds for wealth (panel D). ${ }^{10}$ Higher education seems to decrease loss aversion (panel E), but this effect is only significant in risky loss aversion (Spearman rank order correlations, $p=0.117$ and $p=0.049$, resp.)

\footnotetext{
10 The Spearman rank order correlations are significantly positive at $p<0.0001$ for all four bivariate correlations of income, wealth and $\lambda^{\text {riskless }}$ and lottery choice categories.
} 
and does not eliminate it. Finally, different occupational groups have different degrees of loss aversion (Kruskal-Wallis tests, $p<0.0001$ for both measures).

Of course, bivariate correlations can be misleading. Therefore, we conduct a multiple regression analysis that controls for all available variables and report the findings in Result 6.

Result 6: The socio-demographic variables affect both measures of loss aversion similarly. We find no gender effect and an increase of loss aversion across age cohorts. Higher education decreases loss aversion. Household income and wealth are associated with increases in loss aversion.

Support: We run regressions for both measures of loss aversion. We document the results in Table 2 . We start with $\lambda^{\text {riskless }}$. We estimated three models, using OLS and calculating robust standard errors. In model (1), we only included a dummy for females and age dummies (taking the youngest group (age $\leq 34$ ) as the reference group). We find that females are more loss averse than males, but the difference is not significant (in contrast to the bivariate analysis). Moreover, the older respondents are the more loss averse they get. The age effect is highly significant, in particular for people older than 55 years. ${ }^{11}$ These strong age effects are interesting, both because they may affect financial decision-making across the lifespan (Agarwal et al., 2009) and because they may be related to well-documented decreases in memory performance (Salthouse, 2004). Weber and Johnson (2006) have speculated that such deficits may increase loss aversion in older adults. Of course, our analysis cannot separate these age effects from cohort effects.

Model (2) adds dummies for education and income. We find that higher education reduces loss aversion. Quite surprisingly, higher income is positively correlated with loss aversion. ${ }^{12}$ Regression (3) includes wealth instead of income. ${ }^{13}$ It turns out that higher wealth and loss aversion are also highly significantly positively correlated.

Models (4)-(6) replicate the analysis for our risky choice task using ordered probit estimation. We regress the lottery choice categories (see Table 1) on the same set of explanatory variables as in models (1) to (3). We get very similar results, qualitatively. The only difference arises in model (5) where the middle-income category is not significant for the lottery choice tasks, whereas it is highly significant in the riskless task.

We see the fact that the socioeconomic variables affect $\lambda^{\text {riskless }}$ and the lottery choice category in a qualitatively very similar way as further evidence that both measures reflect a similar underlying psychology-loss aversion. There are strong theoretical arguments why loss aversion underlies the endowment effect and decisions in the lottery choice task. Our dual finding that $\lambda^{\text {riskless }}$ and the lottery

\footnotetext{
${ }_{11}$ At first sight, the result that older people are more loss averse stands in contrast to Kovalchik et al. (2005), who do not find loss aversion in their subject pool of old people (age $>70$ years). However, Kovalchik et al. (2005) note that their old subjects are highly educated relative to their age group. Thus, since education reduces loss aversion, our results might be consistent with those of Kovalchik et al. (2005).

${ }^{12}$ Income and education are positively correlated, but the correlation is surprisingly weak (Spearman's $\rho=0.208)$.

${ }^{13}$ Not surprisingly, income and wealth are significantly positively correlated (Spearman's $\rho=0.437$ ).
} 
Table 2 Socio-economic characteristics and measures of loss aversion

\begin{tabular}{|c|c|c|c|c|c|c|}
\hline \multirow{3}{*}{$\begin{array}{l}\text { Dependent variable } \\
\text { Method }\end{array}$} & \multicolumn{3}{|l|}{$\lambda^{\text {riskless }}$} & \multicolumn{3}{|c|}{ Lottery choice category } \\
\hline & \multicolumn{3}{|l|}{ OLS } & \multicolumn{3}{|c|}{ ordered probit } \\
\hline & (1) & (2) & (3) & (4) & (5) & (6) \\
\hline Female & $\begin{array}{l}0.223 \\
(0.190)\end{array}$ & $\begin{array}{l}0.062 \\
(0.176)\end{array}$ & $\begin{array}{l}0.245 \\
(0.179)\end{array}$ & $\begin{array}{l}0.167 \\
(0.127)\end{array}$ & $\begin{array}{l}0.073 \\
(0.128)\end{array}$ & $\begin{array}{l}0.164 \\
(0.131)\end{array}$ \\
\hline Age $35-54$ & $\begin{array}{l}0.454 * * * \\
(0.151)\end{array}$ & $\begin{array}{l}0.168 \\
(0.171)\end{array}$ & $\begin{array}{l}0.406^{* * * *} \\
(0.148)\end{array}$ & $\begin{array}{l}0.450 * * * \\
(0.169)\end{array}$ & $\begin{array}{l}0.235 \\
(0.195)\end{array}$ & $\begin{array}{l}0.389 * * \\
(0.183)\end{array}$ \\
\hline Age $55+$ & $\begin{array}{l}1.522 * * * \\
(0.332)\end{array}$ & $\begin{array}{l}1.014 * * * \\
(0.304)\end{array}$ & $\begin{array}{l}1.368 * * * \\
(0.318)\end{array}$ & $\begin{array}{l}1.012 * * * \\
(0.194)\end{array}$ & $\begin{array}{l}0.560 * * * \\
(0.210)\end{array}$ & $\begin{array}{l}0.847 * * * \\
(0.205)\end{array}$ \\
\hline High school degree & & $\begin{array}{l}-0.723^{* * *} \\
(0.202)\end{array}$ & $\begin{array}{l}-0.607 * * * \\
(0.201)\end{array}$ & & $\begin{array}{l}-0.403 * * * \\
(0.133)\end{array}$ & $\begin{array}{l}-0.301 * * \\
(0.126)\end{array}$ \\
\hline University degree & & $\begin{array}{l}-1.106^{* * *} \\
(0.265)\end{array}$ & $\begin{array}{l}-0.835 * * * \\
(0.252)\end{array}$ & & $\begin{array}{l}-0.797 * * * \\
(0.229)\end{array}$ & $\begin{array}{l}-0.551 * * * \\
(0.212)\end{array}$ \\
\hline Income Euro $30 \mathrm{k}-70 \mathrm{k}$ & & $\begin{array}{l}0.574 * * * \\
(0.172)\end{array}$ & & & $\begin{array}{l}0.321 \\
(0.216)\end{array}$ & \\
\hline Income Euro $70 \mathrm{k}+$ & & $\begin{array}{l}1.455 * * * \\
(0.245)\end{array}$ & & & $\begin{array}{l}1.214 * * * \\
(0.240)\end{array}$ & \\
\hline Wealth Euro $30 \mathrm{k}-100 \mathrm{k}$ & & & $\begin{array}{l}0.396 * * \\
(0.161)\end{array}$ & & & $\begin{array}{l}0.449 * * \\
(0.176)\end{array}$ \\
\hline Wealth Euro $100 \mathrm{k}+$ & & & $\begin{array}{l}0.910 * * * \\
(0.291)\end{array}$ & & & $\begin{array}{l}0.879 * * * \\
(0.233)\end{array}$ \\
\hline Constant & $\begin{array}{l}1.504 * * * \\
(0.138)\end{array}$ & $\begin{array}{l}1.643 * * * \\
(0.171)\end{array}$ & $\begin{array}{l}1.583 * * * \\
(0.190)\end{array}$ & & & \\
\hline Observations & 310 & 310 & 310 & 326 & 326 & 326 \\
\hline$R^{2}$ & 0.126 & 0.243 & 0.197 & 0.030 & 0.072 & 0.053 \\
\hline
\end{tabular}

Robust standard errors in parentheses. For models (4) to (6), $R^{2}$ refers to the pseudo $R^{2}$

*Significant at $10 \%, * *$ significant at $5 \%$, ***significant at $1 \%$

choices are significantly correlated and that the socio-demographic variables affect both measures in a qualitatively similar way supports the interpretation of observed behavior in terms of loss aversion.

In Mrkva et al. (2020), in survey experiments using risky choice versions of Fig. 1 with 17,360 Americans, we confirm that older people are more loss averse and educated people are less loss averse. Higher income was associated with lower loss aversion, which is the opposite of the finding in Table 2. This suggests that our result on the positive association of income and loss aversion might not be generalizable to other subject pools, whereas the effects of age and education are generalizable. 


\section{Discussion and conclusions}

In this paper, we investigated loss aversion in riskless and risky choices in a large non-student sample (customers of a car manufacturer). To measure loss aversion in riskless choice, we ran endowment effect experiments between and within subjects. We measured loss aversion in risky choice using a simple lottery choice task with low stakes, where a rejection to play a lottery with positive expected value arguably reflects loss aversion rather than risk aversion.

Our results show evidence of loss aversion, both in riskless and risky choices. $82 \%$ of people were loss averse in riskless choice (by showing a WTA/WTPratio $>1$ ); $71 \%$ of people displayed loss aversion in risky choice (by rejecting gambles with positive expected value). Our estimate of median loss aversion in riskless choice is $\lambda^{\text {riskless }}=1.73$. Depending on various assumptions about diminishing sensitivity and probability weighting (Table 1), median loss aversion in risky choice is somewhat lower, between $\lambda^{\text {risky }}=1.15$ and 1.50 . Furthermore, $\lambda^{\text {riskless }}$ and $\lambda^{\text {risky }}$ are positively correlated. However, there is substantial individual heterogeneity in both forms of loss aversion, which socio-demographic variables can explain to some extent: loss aversion is positively correlated with age and wealth, and negatively correlated with higher education. Thus, our results emphasize that the degree of loss aversion can vary across situations (riskless vs. riskless choice) and participants' different socio-demographic characteristics.

Our results, and those of our companion paper (Mrkva et al., 2020), help addressing some of the critiques of loss aversion research: The WTA-WTP disparity might reflect misconceptions (Plott \& Zeiler, 2011); loss aversion has (socio-demographic) moderators and often reflects a status quo bias (e.g., Gal \& Rucker, 2018); and loss aversion in risky choice is highly context dependent (e.g., Ert \& Erev, 2013).

Starting with misconceptions, Plott and Zeiler (2005) argued that the WTA-WTP disparity that lies behind the endowment effect may be due to subjects' misconception of the incentives, unless a union of procedures to control for misperceptions is applied. ${ }^{14}$ Our experiments control for misconceptions because they are incentivized and used simple choice tasks that are very easy to understand. We also used incentive-compatible methods (like the BDM procedure (Becker et al., 1964) and the random lottery procedure (Cubitt et al., 1998). We therefore believe that lack of understanding and incentives, by themselves, are not responsible for the variation we observe. Apart from these methodological points, there are two further reasons why we think so.

First, the two choice problems we study are very different. The choice between gambles involves risk, and a single choice between the status quo and several options. The WTA and WTP tasks involve two valuations of the same single object, each from a different perspective. Despite these differences, they show a high degree of agreement. It is difficult to see what could be the common element of the two methods that is misunderstood. A misunderstanding of strategic considerations, for example, might play a role in the valuation question, but it is less apparent how it

\footnotetext{
$\overline{14}$ See also Isoni et al. (2011) for a discussion of these arguments.
} 
would produce similar results in the choice among gambles. Second, the effect of demographics is similar for these two measures. It seems difficult to reconcile this pattern occurring solely because of miscomprehension.

The systematic influence of socio-demographic variables, in particular age, wealth, and education, suggests that loss aversion has important moderators, some of which increase loss aversion (age, wealth), whereas others decrease it (education). In our companion paper (Mrkva et al., (2020), which studies, among other things, loss aversion with regard to car attributes), we provide further evidence about the importance of moderators, for instance by showing that knowledge and experience (of car attributes) decrease loss aversion. Our joint results suggest that a productive way of proceeding is not to doubt the existence of loss aversion in some economic choice, but to focus on understanding the boundary conditions as some previous research has already started (e.g., Bateman et al., 2005; Haigh \& List, 2005; List, 2003; Novemsky \& Kahneman, 2005). We see this paper and Mrkva et al. (2020) as contributions to our understanding of boundary conditions of loss aversion.

Our results also suggest that loss aversion is one important factor in explaining the endowment effect and it is not just a status quo bias (e.g., Gal \& Rucker, 2018). First, our experimental procedures in testing for the endowment effect do not actually implement a status quo, in particular not in the between-subjects study where participants needed to provide their WTA and their WTP (in random order), and one of them was randomly selected for payment. What is the status quo in this case? Second, the WTA-WTP gap is correlated with loss aversion in risky choice (where the status quo of a zero payoff may serve as a reference point, see Baillon et al., 2020). This correlation reinforces the interpretation that the endowment effect reflects at least some loss aversion. Third, in Mrkva et al. (2020) we provide evidence that experienced car drivers were less loss averse with regard to car attributes than inexperienced drivers. This result challenges status quo bias explanations of loss aversion, because longer experience with a particular car attribute likely makes people more accustomed to it and therefore more likely to develop a status quo bias for it.

Our results on loss aversion in risky choice also speak to a critique that loss aversion is sensitive to the decision context (Ert \& Erev, 2013). For instance, Ert and Erev (2013) found loss aversion in high-payoff gambles, but not in low-payoff gambles like ours. Loss aversion was also more likely when the safe prospect was the status quo; in our case the safe prospect is 0 (by rejecting to play the lottery). Loss aversion is also more likely to arise due to a contrast effect in a choice list design like ours, where the attractiveness of the risky prospects is different between lotteries (it decreases in our choice list, see Fig. 1).

Our Result 4 reports evidence for loss aversion in our low-stakes gambles, although it is lower than loss aversion in riskless choice (Result 5). The loss aversion we observe in our design might therefore be the result of forces that favor it (the choice list, easy-to-calculate expected values, 0 payoff status quo) and design features that hinder it (low payoffs). However, the findings of Ert and Erev (2013) come from student samples which presumably were younger on average than the 
participants in our experiments. If loss aversion increases with age, as our Result 6 suggests, context sensitivity needs to include age as a moderator.

Finally, the evidence of loss aversion that we report in this paper and in Mrkva et al. (2020) reject the idea that loss aversion is a "fallacy" (Gal, 2018). The evidence across our two papers is consistent with neuroscientific evidence (e.g., De Martino et al., 2009; Sheng et al., 2020; Tom et al., 2007), evidence from nonhuman primates (Chen et al., 2006), young children (Harbaugh et al., 2001), smallscale societies (Apicella et al., 2014), and cross-cultural experiments (Wang et al., 2017). This suggests that loss aversion may be deeply rooted, which would imply that for many people it takes experience and learning to overcome loss aversion. Johnson et al. (2007) propose a cognitive account for loss aversion that focuses on the retrieval of aspects of the transaction from memory. Such a cognitive view seems consistent with the observed decrease of loss aversion with education and the increase with age, given the well-documented evidence for cognitive decline.

\section{Appendix}

\section{Questions for eliciting WTA and WTP}

\section{Eliciting WTA:}

In the following question there are no right or wrong answers. Your response should only reflect your own preferences. As the other parts of the questionnaire this following question is part of a scientific research project on how people make economic choices.

We will give you the following little toy car which you can keep.

\section{THIS TOY CAR IS FOR YOU TO KEEP!}

If you do not want to keep the toy car, you can sell it to the organizers of this scientific study. In the table below please mark the minimum acceptable price at which you are willing to sell the car.

- If at our offer price you have indicated in the table that you are willing to sell the toy car, you will receive this amount in cash instead of the toy car.

- If at our offer price you have indicated in the table that you are not willing to sell the toy car, you will keep your toy car.

The price at which we will buy your toy car will be randomly determined and for sure be between $€ 0$ and $€ 10$. That is, our offered price will be determined by rolling dice after you have filled in the table below. All prices are equally likely. There is a scientific reason for proceeding this way. Since you cannot influence the price, which will be determined randomly, you have an incentive to state the price that corresponds to your true preference. Once you have made your choice, you cannot change it anymore. We will also not be able to negotiate about the price. 
Price in $€$

Please make a cross in each line depending on whether you are ready or not to sell the toy car at the respective price to us

\begin{tabular}{|c|c|c|}
\hline If the price is $€ \mathbf{0} \ldots$ & $\ldots$ I am ready to sell & I am not ready to sell: \\
\hline If the price is $€ 0.5 \ldots$ & $\ldots$ I am ready to sell & I am not ready to sell: \\
\hline If the price is $€ \mathbf{1 . 0} \ldots$ & $\ldots$ I am ready to sell & I am not ready to sell: \\
\hline If the price is $€ \mathbf{1 . 5} \ldots$ & $\ldots$ I am ready to sell & I am not ready to sell: \\
\hline If the price is $€ \mathbf{2 . 0} \ldots$ & ... I am ready to sell ___ & I am not ready to sell: \\
\hline If the price is $€ \mathbf{2 . 5} \ldots$ & ... I am ready to sell & I am not ready to sell: \\
\hline If the price is $€ \mathbf{3 . 0} \ldots$ & ... I am ready to sell & I am not ready to sell: \\
\hline If the price is $€ \mathbf{3 . 5} \ldots$ & $\ldots$ I am ready to sell & I am not ready to sell: \\
\hline If the price is $€ \mathbf{4 . 0} \ldots$ & ... I am ready to sell & I am not ready to sell: \\
\hline If the price is $€ \mathbf{4 . 5} \ldots$ & $\ldots$ I am ready to sell & I am not ready to sell: \\
\hline If the price is $\boldsymbol{€} \mathbf{5 . 0} \ldots$ & ... I am ready to sell & I am not ready to sell: \\
\hline If the price is $€ \mathbf{5 . 5} \ldots$ & $\ldots$ I am ready to sell & I am not ready to sell: \\
\hline If the price is $€ \mathbf{6 . 0} \ldots$ & $\ldots$ I am ready to sell & I am not ready to sell: \\
\hline If the price is $€ 6.5 \ldots$ & $\ldots$ I am ready to sell & I am not ready to sell: \\
\hline If the price is $€ 7.0 \ldots$ & $\ldots$ I am ready to sell & I am not ready to sell: \\
\hline If the price is $€ 7.5 \ldots$ & $\ldots$ I am ready to sell & I am not ready to sell: \\
\hline If the price is $€ \mathbf{8 . 0} \ldots$ & ... I am ready to sell & I am not ready to sell: \\
\hline If the price is $€ 8.5 \ldots$ & $\ldots$ I am ready to sell & I am not ready to sell: \\
\hline If the price is $€ 9.0 \ldots$ & $\ldots$ I am ready to sell & I am not ready to sell: \\
\hline If the price is $€ 9.5 \ldots$ & $\ldots$ I am ready to sell & I am not ready to sell: \\
\hline If the price is $€ \mathbf{1 0 . 0} \ldots$ & ... I am ready to sell ___ & I am not ready to sell: \\
\hline
\end{tabular}

\section{Eliciting WTP:}

\section{The questionnaire for eliciting WTP was adapted accordingly.}

Acknowledgements This work was supported by the Economic and Social Research Council [grant number ES/K002201/1], the National Science Foundation [grant number SES-0352062], the National Institute on Aging [grant number 5R01AG027934], the Grundlagenforschungsfonds at the University of St. Gallen and the Institute for Media and Communications Management at the University of St. Gallen. We benefited from excellent research assistance by Esther Kessler, Sabine Müller, Eva Poen and Graziella Zito. We received helpful comments from referees, and Han Bleichrodt, Colin Camerer, Matthew Ellman, Stefano DellaVigna, Armin Falk, Lorenz Götte, Ulrich Schmidt, Chris Starmer, Stefan Trautmann, and participants in various seminars and conferences. We are particularly indebted to Peter Wakker for his encouragement, detailed comments and inspirations over the years.

Open Access This article is licensed under a Creative Commons Attribution 4.0 International License, which permits use, sharing, adaptation, distribution and reproduction in any medium or format, as long as you give appropriate credit to the original author(s) and the source, provide a link to the Creative Commons licence, and indicate if changes were made. The images or other third party material in this article are included in the article's Creative Commons licence, unless indicated otherwise in a credit line to the material. If material is not included in the article's Creative Commons licence and your intended use is not permitted by statutory regulation or exceeds the permitted use, you will need to obtain permission directly from the copyright holder. To view a copy of this licence, visit http:// creativecommons.org/licenses/by/4.0/. 
Author contributions SG, EJ and AH designed the study. AH organized data collection and SG analyzed the data. SG and EJ wrote the paper.

Data availability Data and analysis code are available at https://osf.io/bknc3.

\section{References}

Abdellaoui, M. (2000). Parameter-free elicitation of utilities and probability weighting functions. Management Science, 46, 1497-1512.

Abdellaoui, M., Bleichrodt, H., \& L'haridon, O. (2008). A tractable method to measure utility and loss aversion under prospect theory. Journal of Risk and Uncertainty, 36, 245-266.

Abdellaoui, M., Bleichrodt, H., \& Paraschiv, C. (2007). Loss aversion under prospect theory: a parameterfree measurement. Management Science, 53, 1659-1674.

Agarwal, S., Driscoll, J. C., Gabaix, X., \& Laibson, D. I. (2009). The age of reason: financial decisions over the lifecycle. Brookings Papers on Economic Activity, 2009, 51-117.

Apicella, C. L., Azevedo, E. M., Fowler, J. H., \& Christakis, N. A. (2014). Evolutionary origins of the endowment effect: evidence from hunter-gatherers. American Economic Review, 104, 1793.

Baillon, A., Bleichrodt, H., \& Spinu, V. (2020). Searching for the reference point. Management Science, 66, 93-112.

Bateman, I., Kahneman, D., Munro, A., Starmer, C., \& Sugden, R. (2005). Testing competing models of loss aversion: an adversarial collaboration. Journal of Public Economics, 89, 1561-1580.

Bateman, I., Munro, A., Rhodes, B., Starmer, C., \& Sugden, R. (1997). A test of the theory of referencedependent preferences. Quarterly Journal of Economics, 112, 479-505.

Becker, G. M., Degroot, M. H., \& Marschak, J. (1964). Measuring utility by a single-response sequential method. Behavioral Science, 9, 226-232.

Benartzi, S., \& Thaler, R. H. (1995). Myopic loss aversion and the equity premium puzzle. Quarterly Journal of Economics, 110, 73-92.

Bibby, P. A., \& Ferguson, E. (2011). The ability to process emotional information predicts loss aversion. Personality and Individual Differences, 51, 263-266.

Bleichrodt, H., Abellan-Perpiñan, J. M., Pinto-Prades, J. L., \& Mendez-Martinez, I. (2007). Resolving inconsistencies in utility measurement under risk: tests of generalizations of expected utility. Management Science, 53, 469-482.

Bleichrodt, H., \& Pinto, J. L. (2000). A parameter-free elicitation of the probability weighting function in medical decision analysis. Management Science, 46, 1485-1496.

Bleichrodt, H., \& Pinto, J. L. (2002). Loss aversion and scale compatibility in two-attribute trade-offs. Journal of Mathematical Psychology, 46, 315-337.

Booij, A. S., \& Van De Kuilen, G. (2009). A parameter-free analysis of the utility of money for the general population under prospect theory. Journal of Economic Psychology, 30, 651-666.

Bowman, D., Minehart, D., \& Rabin, M. (1999). Loss aversion in a consumption-savings model. Journal of Economic Behavior \& Organization, 38, 155-178.

Bruhin, A., Fehr-Duda, H., \& Epper, T. (2010). Risk and rationality: uncovering heterogeneity in probability distortion. Econometrica, 78, 1375-1412.

Cachon, G. P., \& Camerer, C. F. (1996). Loss-avoidance and forward induction in experimental coordination games. Quarterly Journal of Economics, 111, 165-194.

Camerer, C. F. (2004). Prospect theory in the wild: evidence from the field. In C. F. Camerer, G. Loewenstein, \& M. Rabin (Eds.) Advances in behavioral economics. Princeton University Press

Camerer, C. F., Babcock, L., Loewenstein, G., \& Thaler, R. H. (1997). Labor supply of New York City cabdrivers: one day at a time. Quarterly Journal of Economics, 112, 407-441.

Carmon, Z., \& Ariely, D. (2000). Focusing on the forgone: how value can appear so different to buyers and sellers. Journal of Consumer Research, 27, 360-370.

Chapman, J., Dean, M., Ortoleva, P., Snowberg, E., \& Camerer, C. (2017). Willingness to pay and willingness to accept are probably less correlated than you think. NBER Working Paper Series \# 23954

Chen, M. K., Lakshminarayanan, V., \& Santos, L. R. (2006). How basic are behavioral biases? Evidence from Capuchin monkey trading behavior. Journal of Political Economy, 114, 517-537. 
Crosetto, P., \& Filippin, A. (2016). A theoretical and experimental appraisal of four risk elicitation methods. Experimental Economics, 19, 613-641.

Cubitt, R. P., Starmer, C., \& Sugden, R. (1998). On the validity of the random lottery incentive system. Experimental Economics, 1, 115-131.

De Martino, B., Kumaran, D., Holt, B., \& Dolan, R. J. (2009). The neurobiology of reference-dependent value computation. The Journal of Neuroscience, 29, 3833-3842.

Dohmen, T., Falk, A., Huffman, D., Sunde, U., Schupp, J., \& Wagner, G. G. (2011). Individual risk attitudes: measurement, determinants, and behavioral consequences. Journal of the European Economic Association, 9, 522-550.

Einiö, M., Kaustia, M., \& Puttonen, V. (2008). Price setting and the reluctance to realize losses in apartment markets. Journal of Economic Psychology, 29, 19-34.

Eisenberger, R., \& Weber, M. (1995). Willingness-to-pay and willingness-to-accept for risky and ambiguous lotteries. Journal of Risk and Uncertainty, 10, 223-233.

Ericson, K. M. M., \& Fuster, A. (2014). The endowment effect. Annual Review of Economics, 6, $555-579$.

Ert, E., \& Erev, I. (2013). On the descriptive value of loss aversion in decisions under risk: six clarifications. Judgment and Decision Making, 8, 214-235.

Fehr, E., \& Goette, L. (2007). Do workers work more if wages are high? Evidence from a randomized field experiment. American Economic Review, 97, 298-317.

Fehr-Duda, H., De Gennaro, M., \& Schubert, R. (2006). Gender, financial risks, and probability weights. Theory and Decision, 60, 283-313.

Freund, C., \& Ozden, C. (2008). Trade policy and loss aversion. American Economic Review, 98, $1675-1691$.

Gal, D. (2006). A psychological law of inertia and the illusion of loss aversion. Judgment and Decision Making, 1, 23-32.

Gal, D. (2018). Why the most important idea in behavioral decision-making is a fallacy. Scientific American, 29, 52-54.

Gal, D., \& Rucker, D. D. (2018). The loss of loss aversion: will it loom larger than its gain? Journal of Consumer Psychology, 28, 497-516.

Genesove, D., \& Mayer, C. (2001). Loss aversion and seller behavior: evidence from the housing market. Quarterly Journal of Economics, 116, 1233-1260.

Goette, L., Huffman, D., \& Fehr, E. (2004). Loss aversion and labor supply. Journal of the European Economic Association, 2, 216-228.

Haigh, M. S., \& List, J. A. (2005). Do professional traders exhibit myopic loss aversion? An experimental analysis. Journal of Finance, 60, 523-534.

Harbaugh, W., Krause, K., \& Vesterlund, L. (2001). Are adults better behaved than children? Age, experience, and the endowment effect. Economics Letters, 70, 175-181.

Hardie, B. G. S., Johnson, E. J., \& Fader, P. S. (1993). Modeling loss aversion and reference dependence effects on brand choice. Marketing Science, 12, 378-394.

Harless, D. W. (1989). More laboratory evidence on the disparity between willingness to pay and compensation demanded. Journal of Economic Behavior \& Organization, 11, 359-379.

Harrison, G., \& Rutström, E. (2009). Expected utility theory and prospect theory: one wedding and a decent funeral. Experimental Economics, 12, 133-158.

He, P., Veronesi, M., \& Engel, S. (2018). Consistency of risk preference measures: an artefactual field experiment from rural China. The Journal of Development Studies, 54, 1955-1973.

Heidhues, P., \& Koszegi, B. (2008). Competition and price variation when consumers are loss averse. American Economic Review, 98, 1245-1268.

Horowitz, J. K., \& McConnell, K. E. (2002). A review of WTA/WTP studies. Journal of Environmental Economics and Management, 44, 426-447.

Huck, S., Kirchsteiger, G., \& Oechssler, J. (2005). Learning to like what you have-explaining the endowment effect. The Economic Journal, 115, 689-702.

Isoni, A., Loomes, G., \& Sugden, R. (2011). The willingness to pay-willingness to accept gap, the "endowment effect," subject misconceptions, and experimental procedures for eliciting valuations: comment. American Economic Review, 101, 991-1011.

Jachimowicz, J. M., Duncan, S., Weber, E. U., \& Johnson, E. J. (2019). When and why defaults influence decisions: a meta-analysis of default effects. Behavioural Public Policy, 3, 159-186.

Johnson, E. J., \& Goldstein, D. (2003). Do defaults save lives? Science, 302, 1338-1339. 
Johnson, E. J., Haeubl, G., \& Keinan, A. (2007). Aspects of endowment: a query theory of value construction. Journal of Experimental Psychology - Learning Memory and Cognition, 33, 461-747.

Johnson, E. J., \& Schkade, D. A. (1989). Bias in utility assessments-further evidence and explanations. Management Science, 35, 406-424.

Kachelmeier, S. J., \& Shehata, M. (1992). Examining risk preferences under high monetary incentivesexperimental evidence from the People's Republic of China. American Economic Review, 82, 1120-1141.

Kahneman, D., Knetsch, J. L., \& Thaler, R. H. (1990). Experimental tests of the endowment effect and the Coase theorem. Journal of Political Economy, 98, 1325-1348.

Kahneman, D., Knetsch, J. L., \& Thaler, R. H. H. (1991). Anomalies-the endowment effect, loss aversion, and status-quo bias. Journal of Economic Perspectives, 5, 193-206.

Kahneman, D., \& Tversky, A. (1979). Prospect theory-analysis of decision under risk. Econometrica, 47, 263-291.

Knetsch, J. L. (1989). The endowment effect and evidence of nonreversible indifference curves. American Economic Review, 79, 1277-1284.

Köbberling, V., \& Wakker, P. P. (2005). An index of loss aversion. Journal of Economic Theory, 122, 119-131.

Köszegi, B., \& Rabin, M. (2006). A model of reference-dependent preferences. Quarterly Journal of Economics, 121, 1133-1165.

Kovalchik, S., Camerer, C. F., Grether, D. M., Plott, C. R., \& Allman, J. M. (2005). Aging and decision making: A comparison between neurologically healthy elderly and young individuals. Journal of Economic Behavior \& Organization, 58, 79-94.

Li, Y., Baldassi, M., Johnson, E. J., \& Weber, E. U. (2013). Complementary cognitive capabilities, economic decision making, and aging. Psychology and Aging, 28, 595-613.

Li, Y., Gao, J., Enkavi, A. Z., Zaval, L., Weber, E. U., \& Johnson, E. J. (2015). Sound credit scores and financial decisions despite cognitive aging. Proceedings of the National Academy of Sciences, 112, 65-69.

Lichtenstein, S., \& Slovic, P. (2006). The construction of preference. Cambridge University Press.

List, J. A. (2003). Does market experience eliminate market anomalies? Quarterly Journal of Economics, $118,41-71$.

Loewenstein, G., \& Adler, D. (1995). A bias in the prediction of tastes. Economic Journal, 105, 929-937.

Morewedge, C. K., \& Giblin, C. E. (2015). Explanations of the endowment effect: an integrative review. Trends in Cognitive Sciences, 19, 339-348.

Mrkva, K., Johnson, E. J., Gächter, S., \& Herrmann, A. (2020). Moderating loss aversion: loss aversion has moderators, but reports of its death are greatly exaggerated. Journal of Consumer Psychology, 30, 407-428.

Novemsky, N., \& Kahneman, D. (2005). The boundaries of loss aversion. Journal of Marketing Research, 42, 119-128.

Odean, T. (1998). Are investors reluctant to realize their losses? Journal of Finance, 53, 1775-1798.

O’Donoghue, T., \& Sprenger, C. (2018). Chapter 1-reference-dependent preferences. In B. D. Bernheim, S. DellaVigna, \& D. Laibson (Eds.) Handbook of behavioral economics: applications and foundations 1.

Plott, C. R., \& Zeiler, K. (2005). The willingness to pay-willingness to accept gap, the "endowment effect," subject misconceptions, and experimental procedures for eliciting valuations. American Economic Review, 95, 530-545.

Plott, C. R., \& Zeiler, K. (2011). The willingness to pay-willingness to accept gap, the "endowment effect," subject misconceptions, and experimental procedures for eliciting valuations: reply. American Economic Review, 101, 1012-1028.

Prelec, D. (1998). The probability weighting function. Econometrica, 66, 497-527.

Rabin, M. (2000). Risk aversion and expected-utility theory: a calibration theorem. Econometrica, 68, $1281-1293$.

Rabin, M., \& Weizsäcker, G. (2009). Narrow bracketing and dominated choice. American Economic Review, 99, 1508-1543.

Read, D., Loewenstein, G., \& Rabin, M. (1999). Choice bracketing. Journal of Risk and Uncertainty, 19, 171-197.

Rozin, P., \& Royzman, E. B. (2001). Negativity bias, negativity dominance, and contagion. Personality and Social Psychology Review, 5, 296-320. 
Salthouse, T. A. (2004). What and when of cognitive aging. Current Directions in Psychological Science, $13,140-144$.

Samuelson, W., \& Zeckhauser, R. (1988). Status quo bias in decision making. Journal of Risk and Uncertainty, 1, 7-59.

Sayman, S., \& Onculer, A. (2005). Effects of study design characteristics on the WTA-WTP disparity: a meta analytical framework. Journal of Economic Psychology, 26, 289-312.

Schmidt, U., Starmer, C., \& Sugden, R. (2008). Third-generation prospect theory. Journal of Risk and Uncertainty, 36, 203-223.

Schmidt, U., \& Zank, H. (2005). What is loss aversion? Journal of Risk and Uncertainty, 30, $157-167$.

Sheng, F., Ramakrishnan, A., Seok, D., Zhao, W. J., Thelaus, S., Cen, P., \& Platt, M. L. (2020). Decomposing loss aversion from gaze allocation and pupil dilation. Proceedings of the National Academy of Sciences, 117, 11356-11363.

Sokol-Hessner, P., Hsu, M., Curley, N. G., Delgado, M. R., Camerer, C. F., \& Phelps, E. A. (2009). Thinking like a trader selectively reduces individuals' loss aversion. Proceedings of the National Academy of Sciences, 106, 5035-5040.

Starmer, C. (2000). Developments in non-expected utility theory: the hunt for a descriptive theory of choice under risk. Journal of Economic Literature, 38, 332-382.

Sugden, R. (2003). Reference-dependent subjective expected utility. Journal of Economic Theory, 111, 172-191.

Tom, S. M., Fox, C. R., Trepel, C., \& Poldrack, R. A. (2007). The neural basis of loss aversion in decision-making under risk. Science, 315, 515-518.

Tovar, P. (2009). The effects of loss aversion on trade policy: theory and evidence. Journal of International Economics, 78, 154-167.

Tunçel, T., \& Hammitt, J. K. (2014). A new meta-analysis on the wtp/wta disparity. Journal of Environmental Economics and Management, 68, 175-187.

Tversky, A., \& Kahneman, D. (1991). Loss aversion in riskless choice-a reference-dependent model. Quarterly Journal of Economics, 106, 1039-1061.

Tversky, A., \& Kahneman, D. (1992). Advances in prospect-theory-cumulative representation of uncertainty. Journal of Risk and Uncertainty, 5, 297-323.

Tversky, A., Sattath, S., \& Slovic, P. (1988). Contingent weighting in judgment and choice. Psychological Review, 95, 371-384.

Wakker, P. P. (2005). Formalizing reference dependence and initial wealth in Rabin's calibration theorem. Working Paper, Econometric Institute, Erasmus University, Rotterdam, The Netherlands. http://people.few.eur.nl/wakker/pdf/calibcsocty05.pdf

Wakker, P. P. (2008). Explaining the characteristics of the power (CRRA) utility function. Health Economics, 17(1329), 1344.

Wakker, P. P. (2010). Prospect theory: for risk and ambiguity. Cambridge University Press.

Wang, M., Rieger, M. O., \& Hens, T. (2017). The impact of culture on loss aversion. Journal of Behavioral Decision Making, 30, 270-281.

Weaver, R., \& Frederick, S. (2012). A reference price theory of the endowment effect. Journal of Marketing Research, 49, 696-707.

Weber, E. U., \& Johnson, E. J. (2006). Constructing preferences from memories. In The construction of preferences, ed. S. Lichtenstein, \& P. Slovic. Cambridge University Press.

Weber, E. U., Blais, A.-R., \& Betz, N. E. (2002). A domain-specific risk-attitude scale: measuring risk perceptions and risk behaviors. Journal of Behavioral Decision Making, 15, 263-290.

Yechiam, E. (2019). Acceptable losses: the debatable origins of loss aversion. Psychological Research Psychologische Forschung, 83, 1327-1339.

Publisher's Note Springer Nature remains neutral with regard to jurisdictional claims in published maps and institutional affiliations. 